$12-2010$

\title{
Fever and Infection in the Neurosurgical Intensive Care Unit
}

\author{
Craig Laws
}

Jack Jallo

Follow this and additional works at: https://jdc.jefferson.edu/jhnj

\section{Let us know how access to this document benefits you}

\author{
Recommended Citation \\ Laws, Craig and Jallo, Jack (2010) "Fever and Infection in the Neurosurgical Intensive Care Unit," JHN \\ Journal: Vol. 5 : Iss. 2 , Article 5. \\ DOI: https://doi.org/10.29046/JHNJ.005.2.005 \\ Available at: https://jdc.jefferson.edu/jhnj/vol5/iss2/5
}

This Article is brought to you for free and open access by the Jefferson Digital Commons. The Jefferson Digital Commons is a service of Thomas Jefferson University's Center for Teaching and Learning (CTL). The Commons is a showcase for Jefferson books and journals, peer-reviewed scholarly publications, unique historical collections from the University archives, and teaching tools. The Jefferson Digital Commons allows researchers and interested readers anywhere in the world to learn about and keep up to date with Jefferson scholarship. This article has been accepted for inclusion in JHN Journal by an authorized administrator of the Jefferson Digital Commons. For more information, please contact: JeffersonDigitalCommons@jefferson.edu. 


\section{Fever and Infection in the Neurosurgical Intensive Care Unit}

\author{
Craig Laws, MS, ${ }^{1}$ Jack I. Jallo, MD, PhD, FACS ${ }^{2}$ \\ ${ }^{1}$ Medical Student, Jefferson Medical College, Thomas Jefferson University \\ 2Department of Neurological Surgery, Thomas Jefferson University, Philadelphia, PA
}

Fever is an adaptive response to a variety of infectious, inflammatory, and foreign stimuli. The "febrile response" confers an immunological advantage to the host over invading microorganisms - bacterial, fungal and viral. Fever results from a cytokine-mediated reaction that results in the generation of acute phase reactants and controlled elevation of core body temperature. The anterior hypothalamus coordinates the "febrile response" in reaction to the release of endogenous pyrogenes and subsequent up-regulation of prostaglandin synthesis. An ensuing change in the hypothalamic set point for temperature regulation advances a synchronized physiologic response from CNS to periphery, on a microscopic and macroscopic level, throughout the entire human organism. This differs from hyperthermia which refers to heat retention attributable to unregulated readjustment of the thermoregulatory mechanism. Clinically, an elevation of core body temperature, whether in fever or hyperthermia, is only the most apparent manifestation of an intricate mechanism that orchestrates activation of autonomic, immunologic, neurologic, hematologic, endocrine and behavioral responses.

Fever has been classically described as having three phases. ${ }^{1}$ In the "initiation phase," cutaneous vasoconstriction diverts blood from the body's surface to its core. Simultaneously, a broad sympathetic impulse commences rigors (shivering) as opposing muscles groups contract to contribute to excess heat production. The shunting of blood from epithelium to core organs and the increase in metabolic activity leads to the elevation of body temperature. In the "plateau phase," heat production and heat loss equalize and the body maintains an elevated temperature through rigors and diaphoresis. In the third phase, or "defervescence," cutaneous vasodilation and diaphoresis lead to dissipation and loss of excess heat, thus allowing the body temperature to drop back to normal.

Hyperthermia occurs when there is disturbances to the central mechanisms of thermoregulation and heat dissipating mechanisms have been compromised. Although the exact mechanisms are unknown, "hyperthermia-induced brain injury" has been speculated to cause direct damage to thermoregulatory centers thus obliterating feedback to the temperature set point elevation. ${ }^{2}$ Some have hypothesized that brain injury induces disruption of mesencephalic-diencephalic physiology responsible for tonic inhibition of thermogenesis and the overriding effects of sympathetic activation which impair peripheral mechanisms of heat dissipation. ${ }^{3}$ Contrary to the normal processes associated with infectious fever, hyperthermia presents as an elevated body temperature in association with the absence of diaphoresis, tachypnea, and tachycardia. ${ }^{4}$ Other characteristics distinguishing hyperthermia from fever include: an inordinately high temperature (greater than $41 \mathrm{C}$ ) that may persist for days to weeks, a lack of diurnal variation, a plateau-like pattern of elevations and maintenance. ${ }^{4}$ Interestingly, appropriate treatment hinges upon correct diagnosis of fever versus hyperthermia, as elevated temperature with hyperthermia is lowered more effectively

Medical Subject Headings from the United States National Library of Medicine

\begin{tabular}{|l|l|}
\hline Fever & $\begin{array}{l}\text { An abnormal elevation of body temperature, usually as a result of } \\
\text { a pathologic process. }\end{array}$ \\
\hline Hyperthermia, induced & $\begin{array}{l}\text { Abnormally high temperature intentionally induced in living things } \\
\text { regionally or whole body. It is most often induced by radiation } \\
\text { (heat waves, infra-red), ultrasound, or drugs. }\end{array}$ \\
\hline Malignant hyperthermia & $\begin{array}{l}\text { Rapid and excessive rise of temperature accompanied by } \\
\text { muscular rigidity following general anesthesia }\end{array}$ \\
\hline
\end{tabular}

by external cooling than by antipyretic agents. Although the causes of this phenomenon remain speculative, the neurologic effects of fever with traumatic brain injury, intracerebral hemorrhage, subarachnoid hemorrhage and post-operative recovery are significant increased temperature has been associated with increased local cytokine activity, increased infarct size, increased intracranial pressure, vasospasm, symptomatic vasospasm, ischemic brain injury and poor outcomes in the acute phase of neurologic injury.

\section{Infectious Fever versus Non-Infectious Fever}

In the NICU setting, fevers are classified as "infectious" or "non-infectious". ${ }^{5}$ Clinicians further characterize them as either "explained" or "unexplained" according to clinical findings, laboratory tests, or imaging studies that elucidate their etiology. ${ }^{6}$ For example, pneumonia is an "explained" and "infectious" cause of fever, confirmed by leukocytosis, purulent tracheal secretion, positive sputum cultures and infiltrate on chest radiograph. On the other hand, atelectasis is an "explained" but "non-infectious" cause of fever confirmed by characteristic findings in two or more lung segments without leukocytosis or positive sputum cultures. Further still, central neurogenic fever or post-traumatic hyperthermia is an "unexplained" and "noninfectious" cause of fever without confirmatory testing or sufficiently descriptive imaging studies. Central fever is speculated to result from damage to hypothalamus, midbrain, or pons enhanced by increased sympathetic activity, opening of the ventricles, damage to the frontal lobes, physical distortion, diffuse axonal injury, or toxic blood metabolites. ${ }^{8}$

\section{Implication of Fever, both Infectious and Non-Infectious, in the NICU}

In the critically-ill neurologic or neurosurgical patient, fever is a double-edged sword, characterized by both beneficial and detrimental effects on the acutely injured central nervous system. The beneficial effects include enhanced resistance to infection, local activation of the coagulation cascade, cytokine-mediated T-cell activation, as well as, neutrophil and macrophage recruitment to injured tissues. In the critically-ill patient, the protective effect of fever 
against the development of infection generally offset the dangers. Unfortunately, the patient that has suffered an acute insult to the CNS is an exception. After the initial injury, secondary brain insults are speculated to be caused by several processes including mitochondrial dysfunction, inflammatory response, free radical generation, and excitatory neurotransmitter release. ${ }^{9}$ These episodes of secondary brain injury appear to be caused by or temporally associated with hypotension, intermittent hypoxia and ischemia, fever and hyperthermia, cerebral hypertension and elevated intracranial pressure. ${ }^{9}$

In terms of trauma to the CNS, it is commonly accepted that elevated temperature exacerbates secondary brain injury. Fever has been demonstrated to increase glutamate release, provoke diffuse oxygen free radical production, increase cytoskeletal protein degradation, and markedly augment the permeability of the bloodbrain barrier. ${ }^{10}$ Increased permeability allows activated immune cells to acquire increased access to the interstitial space. Furthermore, vasogenic edema leads to increased fluid in the extracellular space and accumulation of intracellular fluid resulting in cytotoxic edema. Despite evidence suggesting that hyperthermia does not impact the partial pressure of oxygen ${ }^{11}$ or a causal relationship between elevated brain temperature and increased intracranial pressure, ${ }^{12}$ current therapy suggests otherwise. Fever exacerbates ischemic neuronal damage and physiologic dysfunction after acute traumatic brain injury, subarachnoid hemorrhage, and major neurosurgery. ${ }^{13}$ In addition to the aforementioned effects, fever also increases circulating catecholamines boosting cardiovascular output to meet heightened metabolic demands, further taxing the already damaged CNS. In sum, the physiologic response to fever in the CNS has been assumed to contribute deleterious effects that exceed any potential benefits of staving off infection.

\section{Relevance to the Neurosurgical Patient}

At least half of febrile incidents in the ICU are of non-infectious origin ${ }^{5}$ In the neurocritical and neurosurgical patients the incidence and prevalence of non-infectious fever are even greater. Febrile episodes occur in roughly $50 \%$ of patients in the NICU with neurocritical patients having a slightly lower frequency of fever, approximately $23 \%$, ${ }^{6}$ than patients in the neurosurgical ICU, approximately $47 \%{ }^{14}$

Fever in the neurocritical and neurosurgical patient population predominates with vascular injuries, such as intracerebral hemorrhage and subarachnoid hemorrhage. The highest rates of febrile episode occur in patients with subarachnoid hemorrhage (65\%), followed by traumatic brain injury (40\%) and intracranial hemorrhage ( $31 \%)$; no cause of fever was identified in $28 \%$ of patients, suggesting fever of central origin. ${ }^{6}$

Fever has been linked to an increase in the length of stay, subsequent onset of further febrile episodes. Multiple studies have demonstrated that "non-infectious fever" is common in both the neurocritical and neurosurgical ICU patient population. Fever also tends to predominate amongst patients that have suffered either intracranial injury or traumatic brain injury as compared to spinal disorders.

\section{Infectious Fever in the NICU}

A new fever in an ICU patient can have a multitude of infectious and non-infectious etiologies. The practice guidelines from the Task Force of the Society for Critical Care Medicine (SSCM) and Infectious Disease Society of America (IDSA) urge for a "careful clinical assessment" and "cost-conscious approach" to obtaining a diagnosis through laboratory or radiological tests. ${ }^{15}$ The SSCM and IDSA Task Force recommend perpetual reflection on the impact of diagnostic testing and radiological imaging with respect to patient harm, further nosocomial infection risks, and the likelihood of legitimate life-sparing intervention. They argue that "infection be considered regardless of temperature but that laboratory tests for infection should be initiated for febrile patients only if clinical assessment indicates a reasonable possibility that infection might be present". ${ }^{15}$

The common causes of infectious fever in a NICU patient are the same as those for any critically ill patient. However, specific considerations should be made for nosocomoial infections secondary to depressed level of consciousness and surgical opening of the cranial vault. In a 2003 article, Commichau et al. ${ }^{6}$ reported that fever was associated with infection in $50 \%$ of the 387 patients admitted to the Columbia University Hospital NICU. In a European 2002 study, Stochetti et al. ${ }^{10}$ reported similar infection rates, again acknowledging pneumonia as the most frequent infection in head-injured patients. The most common infectious causes of fever in the NICU (10-20\% of patients in the ICU) are presented in Table I.

The high incidence of nosocomial infections (NI) amongst patients admitted to Intensive Care Units (ICUs) are equally relevant to patients admitted to Neurocritical and Neurosurgical ICUs (NICUs). In the neurocritical and neurosurgical patient populations, nosocomial infection rates also depend on the severity of illness at presentation (i.e, Grade of $\mathrm{SAH}$ ) and the exposure to invasive devices such as ventilators, central venous catheters and urinary catheters in addition to neuroscience specific devices, such as ventricular catheters. In the U.S., nosocomial infection rates in ICUs are tracked by the "National Nosocomial Infections Surveillance" System (NNIS) run by and published annually by the CDC. Unfortunately, the NNIS does not collect or analyze data specific to the NICU setting, thus there is a paucity of data available on the incidence of NI in the neurocritical or neurosurgical patient population.

In 1997, Dettenkofer et al. ${ }^{16}$ began a prospective study in a ten-bed NICU tracking the incidence of nosocomial infections over a 30-month study period. They reported data on 505 patients with a total of 4,873 patient days and $122 \mathrm{NI}$ amongst 96 patients (74 patients with one NI, 18 patients with two NI's, 4 patients with three NI's). The overall incidence of NI in the NICU was $24 \%$ (24.2 per 100 patients with a incidence density of 25.0 per 1,000 patient days), with nosocomial pneumonia $(11.7 \%)$ and urinary tract infections (8.7\%) the most frequent cause of infection, respectively. Interestingly, of the 59 nosocomial pneumonias, only 22 (37\%) were ventilator-associated while 37 (63\%) non-ventilator-associated. Contrary to data on medical-surgical ICUs, more than half the cases of nosocomial pneumonia were non-ventilator associated, which corresponds to decreased ventilator usage among NICU patients. Furthermore, the incidence of nosocomial pneumonias can probably be accounted for by the known high risk of aspiration pneumonia for patients with a depressed level of consciousness. With respect to UTI's, the incidence of NI's were strongly associated with device utilization (42 of 44 UTI's were device-associated). The incidence of bloodstream infections and other catheter related infections (local infections) were relatively low when compared to the incidence of pneumonias and UTI's (1.4\% and $1.2 \%$, respectively). Finally, the incidence of ventriculitis and meningitis were also extremely low $(0.8 \%$ and $0.4 \%$, respectively) when also compared to other NI's.

\section{Non-Infectious Fever in the NICU, Explained and Unexplained Etiology}

The patient with classic protracted fever in the NICU setting requires a methodical approach. Given the ramifications, an infectious cause is always presumed and its etiology sought for any critically ill patient with new onset of fever 
Table 1

\begin{tabular}{|c|c|c|c|}
\hline & Indication & Work-Up & Notes \\
\hline $\begin{array}{l}\text { Pneumonia: } \\
\text { Ventilator-Assisted Pneumonia: } \\
\text { occurs in } ~ 25 \% \text { of mechani- } \\
\text { cally ventilated medical-surgical } \\
\text { ICU patients; Pulmonary infec- } \\
\text { tions (bronchitis and pneumonia) } \\
\text { accounted for } 82 \% \text { of all infections } \\
\text { and were the predominant cause } \\
\text { of fever in patients with stroke; }\end{array}$ & $\begin{array}{l}\text { leukocytosis, purulent tracheal } \\
\text { secretions, purulent sputum, } \\
\text { decreased breath sounds, rales on } \\
\text { rhonchi, new or worsening infil- } \\
\text { trates on chest radiograph }\end{array}$ & $\begin{array}{l}\text { Chest imaging study-chest radio- } \\
\text { graph and/or CT scan (if otherwise } \\
\text { indicated) } \\
\text { Cultures of secretions from LRTI } \\
\text { before administration of antibiotic } \\
\text { Cultures: Epectorated sputum, } \\
\text { tracheal secretions, broncheoal- } \\
\text { veolar lavage }\end{array}$ & $\begin{array}{l}\text { In cases of co-morbid pleural } \\
\text { effusion, thoracentesis if sufficient } \\
\text { volume or juxtapositioned near } \\
\text { lobar consolidation, stain, culture } \\
\text { and cytology of pleural fluid }\end{array}$ \\
\hline $\begin{array}{l}\text { Bloodstream Infections: } \\
\text { In absence of IV-line or catheters, } \\
\text { bloodstream infections typically } \\
\text { arise from gastrointestinal and } \\
\text { genitourinary tracts flora. }\end{array}$ & $\begin{array}{l}\text { Any new patient with fever; even } \\
\text { when clinical findings do not } \\
\text { strongly suggest a non-infectious } \\
\text { cause, because positive culture } \\
\text { has important prognostic and } \\
\text { therapeutic implications }\end{array}$ & $\begin{array}{l}\text { No more than three blood samples } \\
\text { (10-15 ml each) for culture need to } \\
\text { be drawn during the first } 24 \text { hours } \\
\text { after fever onset, and two blood } \\
\text { samples should generally suffice; } \\
\text { draw at least two blood samples } \\
\text { from separate venipuncture sites } \\
\text { at least ten minutes apart using } \\
\text { proper sterile techniques }\end{array}$ & \\
\hline $\begin{array}{l}\text { Intravenous Catheter-Related } \\
\text { Infection: } \\
\text { Stable catheters with good } \\
\text { vascular access are a mainstay } \\
\text { of treatment for the critically-ill. } \\
\text { Infections caused by pathogens } \\
\text { that have colonized an indwelling } \\
\text { vascular device (tunneled, surgi- } \\
\text { cally implanted, cuffed central } \\
\text { venous, or subcutaneous central } \\
\text { venous port) can cause localized } \\
\text { or systemic infection }\end{array}$ & $\begin{array}{l}\text { Difficulty drawing or infusing } \\
\text { through the catheter site, inflam- } \\
\text { mation at the insertion site; } \\
\text { Recovery of microorganisms } \\
\text { from the blood at multiple blood } \\
\text { cultures; Rapid onset of infection } \\
\text { associated with fulminant shock; } \\
\text { Multiple positive blood cultures }\end{array}$ & $\begin{array}{l}\text { Again, no more than three blood } \\
\text { samples (10-15 ml each) for } \\
\text { culture need to be drawn during } \\
\text { the first } 24 \text { hours after fever onset, } \\
\text { and two blood samples should } \\
\text { generally suffice; draw at least } \\
\text { two blood samples from separate } \\
\text { venipuncture sites at least ten } \\
\text { minutes apart using proper sterile } \\
\text { techniques; infection at the insertion } \\
\text { site as evidence by inflammation } \\
\text { or purulence at the exit site or an } \\
\text { intravascular site (cultures and } \\
\text { thrombosis) }\end{array}$ & \\
\hline $\begin{array}{l}\text { Sinusitis: } \\
\text { Occurs in } 5 \% \text { of ICU patients, but } \\
\text { with increased frequency in neuro- } \\
\text { surgical patients secondary to } \\
\text { chronic intubation and NG tubes }\end{array}$ & $\begin{array}{l}\text { Cough and leukocytosis with } \\
\text { purulent nasal discharge, maxillary } \\
\text { facial tenderness, periorbital } \\
\text { edema, headache, tooth pain, } \\
\text { earache, sorethroat, foul breath, } \\
\text { wheezing }\end{array}$ & $\begin{array}{l}\text { Remove nasotracheal or nasogastric } \\
\text { tube placement, nasal packing, CT } \\
\text { scan, coronal radiographs, or MRI, } \\
\text { puncture and aspiration of sinuses } \\
\text { under sterile conditions, gram stain } \\
\text { and culture of organisms }\end{array}$ & $\begin{array}{l}\text { Risk factors include facial } \\
\text { fractures, steroid administration, } \\
\text { NG/NT tubes, neurosurgery }\end{array}$ \\
\hline $\begin{array}{l}\text { Nosocomial Diarrhea: } \\
\text { Most common febrile diarrhea } \\
\text { in the ICU is Clostridium difficile; } \\
\text { Antibiotic administration associ- } \\
\text { ated diarrhea (check medical } \\
\text { record for previous use of } \\
\text { Clindamycin or Cephalosporin or } \\
\text { Fluoroquinolones) }\end{array}$ & $\begin{array}{l}2+\text { stools per day that conform to } \\
\text { the container }\end{array}$ & $\begin{array}{l}\text { Remove offending AB agent; diag- } \\
\text { nosis via "Gold Standard" is tissue } \\
\text { culture from stool sample; Elisa } \\
\text { Immunoassay test for toxins, Rapid } \\
\text { C-Diff Test, gram stain and culture } \\
\text { of organisms }\end{array}$ & $\begin{array}{l}\text { Diarrhea is caused by enteral } \\
\text { feeding, antibiotic overuse or } \\
\text { infectious causes }\end{array}$ \\
\hline
\end{tabular}


Table 1 continued

\begin{tabular}{|c|c|c|c|}
\hline & Indication & Work-Up & Notes \\
\hline $\begin{array}{l}\text { Urinary Tract Infections: } \\
\text { Urinary tract disease in the } \\
\text { presence of bladder catheters, } \\
\text { obstruction of the urethra, bladder } \\
\text { or ureters, leukocyte esterase } \\
\text { dipstick test }\end{array}$ & $\begin{array}{l}\text { Pyuria, leukocytosis, purulent } \\
\text { discharge from urethral meatus, } \\
\text { obstructive symptoms, retention } \\
\text { symptoms, suprapubic tenderness, } \\
\text { costovertebral angle tenderness, } \\
\text { change in mental status, fluid } \\
\text { retention, edema, headache, } \\
\text { change in mental status }\end{array}$ & $\begin{array}{l}\text { Urine Culture (clean catch or urine } \\
\text { port), remove pre-existing Foley } \\
\text { catheter, gram stain or urinary } \\
\text { sediment, and culture of organisms }\end{array}$ & \\
\hline Surgical Site Infections & $\begin{array}{l}\text { purulent discharge, tenderness, } \\
\text { dehiscence, erythema, purulence, } \\
\text { or tenderness }\end{array}$ & $\begin{array}{l}\text { Examine surgical wound; Remove } \\
\text { drains or packing, open the } \\
\text { wound, aspirate under sterile } \\
\text { conditions, irrigate; Gram stain and } \\
\text { culture of organisms from pus or } \\
\text { material deep within the wound site }\end{array}$ & \\
\hline CNS Infection & $\begin{array}{l}\text { Leukocytosis and alterations in } \\
\text { neurological parameters, change } \\
\text { in mental status, focal findings, } \\
\text { absence of neurological findings, } \\
\text { lateral shift of midline structures } \\
\text { on imaging study, loss of supra- } \\
\text { chiasmatic and basilar cisterns, } \\
\text { obliteration of the fourth ventricle }\end{array}$ & $\begin{array}{l}\text { CT scan or MRl; Lumbar Puncture, } \\
\text { determination of glucose, protein } \\
\text { and LDH, Gram stain, white cell } \\
\text { count and culture of CSF }\end{array}$ & Takes a high index of suspicion \\
\hline
\end{tabular}

in NICU. However, there are equally legitimate noninfectious causes that must be considered as well.

Avoidance of fever and hyperthermia remains a major aim in the management of patients in the NICU. However, this goal is not commonly achieved given the uncertain etiology of a potentially infectious or non-infectious fever. A fundamental principle in this setting is that the management of a classic fever of unknown origin is that "therapy should be withheld, whenever possible, until the cause of fever has been determined, so that it can be tailored to a specific diagnosis"?

Within the non-infectious etiologies, there are four subcategories of non-Infectious fever which are the following:

1. Non-Infectious Inflammatory Disease: Autoimmune Diseases, Rheumatologic Phenomenon,

2. Neoplastic Disease:

Primary CNS Tumors and Malignancies, Leukemias and Lymphomas, Metastatic Disease, Oncologic Diseases
3. Pharmacologic Causes:

Drug Fever, Withdrawal Syndromes, Neuroleptic Malignant Syndrome, Malignant Hyperthermia, Chemical Meningitis, Drug Toxicities

4. Post-Traumatic or Peri-Operative: Central Fever, Neurogenic Fever, Aseptic Meningitis, Atelectasis or ARDS without Pneumonia, Deep Venous Thrombosis, Posterior Fossa Syndrome

Fever is typical in a variety of acute and chronic neurological disorders confronted in the neurocritical and neurosurgical patient population. Copious experimental evidence suggests that fever is associated with neuronal injury in conditions such as cerebral ischemia, subarachnoid hemorrhage, intracerebal hemorrhage, peri-operative neurosurgical recovery and traumatic brain injury. However, conclusive evidence linking control of non-infectious fever to improved outcomes has inherent difficulties because central neurogenic fever and posttraumatic hyperthermia are diagnoses of exclusion demanding a thorough previous infectious work-up. The impact of fever control in the
NICU is at the mercy of a veteran clinician with a high index of suspicion because traditional methods of fever control are ineffective.

\section{Treatment Dilemma: "To treat or not to treat"}

In NICU patients with fever, the clinical sign of pneumonia, bacteremia, sinusitis, UTI, or meningitis or ventriculitis should direct the therapy and choice of an appropriate antibiotic relatively immediately. First, all cultures should be obtained, while all central lines placed for $>48$ hours and the nasal tube should be removed and cultured using semiquantitative or quantitative cultures. If fever persists for 48-96 hours after antibiotic treatment and without the cause or source of the infection being identified, the patient should be reevaluated for risk factors associated with fungal infection (initiation of empiric antifungal treatment is indicated), while additional diagnostic test, including venography, CBC with differential and eosinophil count, and abdominal imaging are indicated.

During recent years, several biomarkers have been proposed as adjunctive markers for the evaluation of fever, aiming to discriminate 
between an infectious cause from a noninfectious reaction or clandestine inflammatory diseases. The biomarkers include: serum procalcitonin assays with variable cutoffs, endotoxin detection systems, triggering receptor expressed on myeloid cells-S (TREM-1), $\mathrm{C}$-reactive protein (CRP), tumor necrosis factor- $\alpha$, and interleukin- 6 . From all the above biomarkers, serum procalcitonin assay is approved for early detection of bacterial infection/sepsis during the first day of ICU admission, while the rest have yet to be validated.

The treatment of neurocritical or neurosurgical patients with central neurogenic fever hinges upon the axiomatic decision to declare a fever to be of infectious or non-infectious cause. For instance, to operate on the presumption that a patient has an infection until proven otherwise demands the utilization of rigorous empiric antibiotics regimens. The use of these medications is far from benign. In the ICU setting with all its innate risk factors for nosocomial infections, empiric antibiotic utilization can lead the patient to be unnecessarily exposed to courses of antibiotics with inherent toxicities, drug interactions and side effects that are conceivably detrimental to recovery or elucidation of the fevers origin. Furthermore, a response to antibiotics is an unreliable criterion for diagnosing or excluding bacterial or viral CNS infection, especially in the context of neurocritical or neurosurgical patients with intrinsic risks for non-infectious fever anyway.

\section{Conclusion: Treatment Implications of Infectious versus Non-Infectious Fever}

Clinical signs of fever are frequent in neurocritical and neurosurgical patients, and antibiotics are often administered without proof of infection. The clinical characteristics of patients with infectious fever and non- infectious fever markedly overlap. Classical markers of infection cannot differentiate reliably between inflammation and infection after neurosurgery. ${ }^{17}$ The neurosurgical patient having suffered a CNS insult but lacking a documented source of fever, has a central neurogenic fever or post-traumatic hyperthermia by definition. To make the diagnosis of non-infectious unexplained fever (central neurogenic fever or post-traumatic hyperthermia) the clinician must have a high index of suspicion. On the NICU, the clinician combats inherent limitations of the physical exam and neurological exam, while racing against the incubation period for cultures, and exponential growth curve of infectious organisms in vivo. The critical sequelae of either untreated infections or unmanaged central neurogenic fever are urgent dilemmas in the neurocritical and neurosurgical intensive care setting. Regardless, the adverse effects of temperature elevation on neurological recovery are clear. The maxim that "time is tissue" and now "temp is tissue" demands further investigation and further trials of antipyretic medications, anti-hyperthermia strategies such as intravascular cooling techniques in addition to surgical interventions for tissue sparing before the onset of further ischemic damage or coagulative necrosis in the CNS.

\section{References}

1. Aiyagari, $V$ and Diringer M. (2007). Fever control and its impact on outcomes: What is the evidence? Journal of the Neurological Science, 261, 39-46.

2. Tauber MG and Moser B. (1999). Cytokines and chemokines in meningeal inflammation: Biology and clinical implications. Clinical Infectious Disease, 28, 1-11.

3. Rabinstein, AA and Sandhu K. (2006). Non-infectious fever in the neurological intensive care unit: incidence, causes, and predictors. Journal of Neurology, Neurosurgery and Psychiatry, 78, 1278-1280.
4. Childers MK, Upright J and Smith DW. (1994). Posttraumatic hyperthermia induced brain injury rehabilitation. Brain Injury, 8(4), 335-343.

5. Dimopoulos, G and Falagas ME. (2009). Approach to the febrile patient in the ICU. Infectious Disease Clinics of North America, 23, 471-484.

6. Commichau C, Scarmeas N and Mayer SA. (2003). Risk factors for fever in the neurological intensive care unit. Neurology, 60, 837-841.

7. Bryan CS and Ahuja D. (2007). Fever of Unknown Origin: Is there a role for empiric therapy? Infectious Disease Clinics of North America, 21, 1213-1220.

8. Shibata M. (1998). Hyperthermia in brain hemorrhage. Medical Hypothesis, 50, 185-190.

9. O'Phelan $\mathrm{KH}$ et al. (2009). Patterns of increased intracranial pressure after severe traumatic brain injury. Neurocritical Care, 10, 280-286

10. Stochetti $\mathrm{N}$ et al. (2002). Pyrexia in head-injured patients admitted to intensive care. Intensive Care Medicine, 28, $1555-1562$.

11. Spiotta AM, Stiefel MF, Heuer GG, Bloom S, MaloneyWilensky E, Yang W, Grady MS, LeRoux PD. (2008). Brain hyperthermia after traumatic brain injury does not reduce brain oxygen. Neurosurgery, 62: 864-872.

12. Huschak, G, Hoell T, Wiegel M, Hohaus C, Stuttman R, Meisel HJ and Mast H. (2008). Does brain temperature correlate with intracranial pressure? Journal of Neurosurgery and Anesthesiology, 20(2), 105-109.

13. Ginsberg MD and Busto R. (1998). Combating hyperthermia in acute stroke: a significant clinical concern. Stroke, 29, 529-534.

14. Kilpatrick MM, Lowry DW, Firlik AD, Yonas H and Marion DW. (2000). Hyperthermia in the neurosurgical intensive care unit. Neurosurgery, 47, 850-856.

15. O'Grady NP et al. (1998). Practice Guidelines for Evaluating New Fever in Critically Ill Adult Patients. Clinical Infectious Disease, 26, 1042-1059.

16. Dettenkofer, M, Ebner S, Els T, Babikir R, Lucking C, Pelz K, Rüden H, and Daschner F. (2001). Surveillance of nosocomial infections in a neurology intensive care unit. Journal of Neurology, 248, 959-964.

17. Laifer et al. (2005). Dynamics of Serum Procalcitonin in patients after major neurosurgery. Clinical Microbiology and Infection, 11(8), 679-681. 